\title{
Renal Tubular Acidosis Associated With Deafness
}

National Cancer Institute

\section{Source}

National Cancer Institute. Renal Tubular Acidosis Associated With Deafness. NCI

Thesaurus. Code C123219.

Renal tubular acidosis associated with sensorineural hearing loss, and which is typically associated with recessive mutations. 